\title{
DETECÇÃO PELO TESTE IMUNOENZIMÁTICO ELISA DE ANTICORPOS IgM ANTI-CYSTICERCUS CELLULOSAE NO LIQUIDO CEFALORRAQUEANO NA NEUROCISTICERCOSE
}

\author{
JULIA M. COSTA * \\ R. MINEO * \\ J. A. LIVRAMENTO ** \\ M. E. CAMARGO ***
}

A neurocisticercose humana apresenta sintomatologia polimorfa que muitas vezes dificulta o diagnóstico clínico e na maioria dos casos o diagnóstico pode ser confundido com outras patologias, contribuindo para que os casos detectados sejam em número menor que o real. A segurança diagnóstica pela evidenciação do parasita em ato cirúrgico ou por exames como a tomografia computadorizada contrasta com a simplicidade dos testes imunológicos, ainda que sujeitos a limitações. $\mathrm{Na}$ impossibilidade de demonstração direta do parasita, os métodos imunológicos adquirem indubitável valor, uma vez que a presença de anticorpos circulantes oferece indicação indireta da infecção, mesmo antes de suas manifestações clínicas. Diversos métodos imunológicos têm sido apiicados à pesquisa de anticorpos anti-cisticerco no líquido cefalorraqueano (LCR) $3,4,5,11,13,14,16,17,20,23$, porém, não têm sido caracterizadas as classes de imunoglobulinas resultantes da resposta humoral. Martínez-Cairo et col. ${ }^{13}$. utilizando método de imunodifusão radial e Spina-França e Kleine 24 com o método da imunonefelometria demonstraram o aumento da concentração de IgG, IgM, e IgA em amostras de LCR de pacientes com neurocisticercose. O teste imunoenzimático "ELISA" (Enzyme Linked ImmunoSorbent Assay) pela alta sensibilidade, especificidade e reprodutibilidade vem sendo aplicado ao diagnóstico da cisticercose ${ }^{13}$ e neurocisticercose 8,10 possibilitando a quantificação da imunoglobulina $\mathbf{G}$ específica.

No presente trabalho foram pesquisados anticorpos $\operatorname{IgM}$ anti-C. cellulosae em amostras de LCR, pelo teste imunoenzimático com o propósito de no futuro investigar seu significado como indice de doença em atividade. Foram comparados os niveis de anticorpos IgM e IgG detectados pelos testes imunoenzimáticos específicos. Paralelamente, compararam-se os resultados dos testes ELISA com os de hemaglutinação, imunofluorescência e fixação do complemento para neurocisticercose.

Trabalho realizado no Centro de Ciências Biomédicas do Departamento de Ciências Biológicas da Universidade de Uberlândia * com a colaboração do Centro de Investigações em Neurologia ** e do Instituto de Medicina Tropical *** da Faculdade de Medicina da Universidade de São Paulo. 


\section{MATERIAL E MÉTODOS}

Antigeno glicoproteico de Cysticercus cellulosae - Cisticercos foram obtidos a partir de músculo esquelético de suinos com infeç̧ão natural maciça. Os parasitas, separados por dissecção, resultaram em cisticercos integros que após 4 lavagens em solução salina (NaC1 0,15M) foram congelados em nitrogênio líquido e conservados a -700C. Preparou-se o extrato glicoproteico de $C$. cellulosae segundo metodologia semelhante à descrita por Nash e col. 22. Adicionaram-se a 50 cisticercos, $10 \mathrm{ml}$ de $\mathrm{NaOH} 0,2 \mathrm{~N}$. Após trituração por 10 minutos em homogeneizador elétrico Sorvall, seguiu-se tratamento com ultrassorn por dois minutos em banho de gelo. O produto sonicado foi mantido sob agitação lenta por duas horas à temperatura ambiente. Centrifugou-se por 20 minutos a $8.500 \mathrm{~g}$ e apis desprezar o sedimento, adicionaram-se ao sobrenadante três volumes de etanol $99 \%$ gelado. A mistura foi deixada a $4 \circ \mathrm{C}$ por 24 horas. Após nova centrifugação e lavagens com etanol gelado, foram adicionados ao sedimento $10 \mathrm{ml}$ de agua destilada $\mathrm{e}$ igual volume de ácido tricloroacético a $15 \%$. Após 18 horas a $40 \mathrm{C}$ o precipitado formado foi removido por centrifugação a $8.500 \mathrm{~g}$ por 20 minutos sendo o sobrenadarite cuidadosamente neutralizado com solução de $\mathrm{NaOH}$, de inicio a $3 \mathrm{~N}$ e depois a $0,2 \mathrm{~N}$ e dialisado contra água destilada por 24 horas. Precipitados eventuais foram retiradcs por centrifugaçäo e o material dosado pelos métodos de Antrona 19 e Lowry 15. O material foi então distribuído em aliquotas de $1 \mathrm{ml}$ e conservado a $-70 \mathrm{C}^{\mathrm{C}}$. Liquido cefalorraqueano Foram estudados 41 amostras de LCR: 26 de pacientes com neurocisticercose; 5 de pacientes com neurossifilis; 10 de pessoas aparentemente normais e que não apresentavam qualquer tipo de alteracão no exame do LCR. As amostras do LCR foram centrifugadas a $2.500 \mathrm{~g}$ e separadas em alíquotas de $1 \mathrm{ml}$, sendo armazenados a -200c. Conjugado anti-IgM humano-peroxidase - As imunoglobulinas da classe IgM, obtidas a partir de soro de paciente com mielona M monoclonal, foram isoladas segundo método descrito por Michele e Isliker 21 e inoculadas em carneiro. Purificou-se o antissoro obtido segundo técnica descrita por Avrameas e Ternynck 2. O antissoro específico para cadeias $\mu$ foi então marcado com peroxidase (Horseradish peroxidase, Tipo VI, Sigma Chemical Co. USA) pela técnica de Wilson e Nakane 25. O conjugado obtido foi titulado em presença de LCR reativo e não reativo para neurocisticercose. Considerou-se o título como a diluição (de razão 2) anterior à maior diluição ainda capaz de fornecer reatividade máxima para a amostra reagente e ausência da reação inespecífica para a amostra não reagente. Teste imunoenzimático ELISA-IgM - Empregaram-se placas de polivinil (Plásticos Ampla, são Paulo, Brasil) como suporte à absorção do antígeno glicoproteico. As placas foram sensibilizadas a $4 \circ \mathrm{C}$ durante 18 horas com $0,2 \mathrm{ml}$ de solução de antígeno na concentração de $20 \mu \mathrm{g} / \mathrm{ml}$, em tampão carbonuto-bicarbonato 0,03 M pH 9,6. Para controle, sensibilizou-se a placa somente com o támpão de diluição. Após esse período e lavagens em PBS-Tween 20 a $0,05 \%$ foram adicionadas $0,2 \mathrm{ml}$ das amostras de LCR não diluídas e diluídas na razão 2 e incubou-se por 45 minutos a $370 \mathrm{C}$. Após lavagens das placas com PBS-Tween, adicionou-se o conjugado no título de 1/800 e incubou-se por 45 minutos a 370C. Após novas lavagens a reação foi revelada pela adição de $0,2 \mathrm{ml}$ de substrato constituído de $1,47 \mathrm{mM}$ de $\mathrm{H}_{2} \mathrm{O}_{2}$ e $5,23 \mathrm{mM}$ de ácido 5-amino-salicílico e após uma hora a temperatura ambiente procedeu-se à leitura. Esta se fazia por inspeção visual direta das placas, em comparação com LCR padrão, positivo e negativo paralelamente ensaiados. Tomava-se como título a maior diluição de LCR forne- 
cendo coloração. No LCR negativo observava-se total ausência de cu'oração em qualquer das diluiçóes, enquanto que muito visível e de grande intensidade nas baixas diluições dos LCR reagente. Tratamento dos LCR com 2-mercaptoetanol - Procedeu-se ao tratamento dos LCR positivos com 2-mercaptoetanol (2ME) para verificação da especificidade do teste quanto a deteçãa da imunoglobulina M. Adicionou-se a $0,2 \mathrm{ml}$ de LCR, $0,4 \mathrm{ml}$ de $2 \mathrm{ME}$ para solução final de $0,07 \mathrm{M}$. Obteve-se $\mathrm{LCR}$ na diluição inicial de $1 / 3$ e diluições seriadas na razão 2. Após uma hora a $370 \mathrm{C}$ em banho maria as amostras foram analisadas pelo teste ELISA-IgM. Teste imunoenzimático ELISA-IgG - Procedeu-se a análise dos LCR pelo teste imunoenzimático ELISA-IgG, segundo Costa e col. 9, utilizando-se como antígeno o extrato salino total de $C$. cellulosae. Outros testes Realizou-se a reação de fixação de complemento pela técnica de Koìmer e col. 12 com antígeno metílico de $C$. cellulosae (Lio-Serum, Ribeirão Preto, São Paulo, Brasil). Para reação de imunofluorescência indireta utilizaram-se como antígeno cortes de 4 micra de cisticercos incluidos em Tissue Teck O.C.T. (Ames Co. Miles Laboratory, Indiana, USA) e como conjugado antiglobulina humana marcada com isotiocianato de fluoresceina pela técnica de Clark e Shepard 7. A reação de hemaglutinação com hemácias sensibilizadas com líquido de vesícula de cisticercos fai realizada como descrito por Camargo e col. 6 .

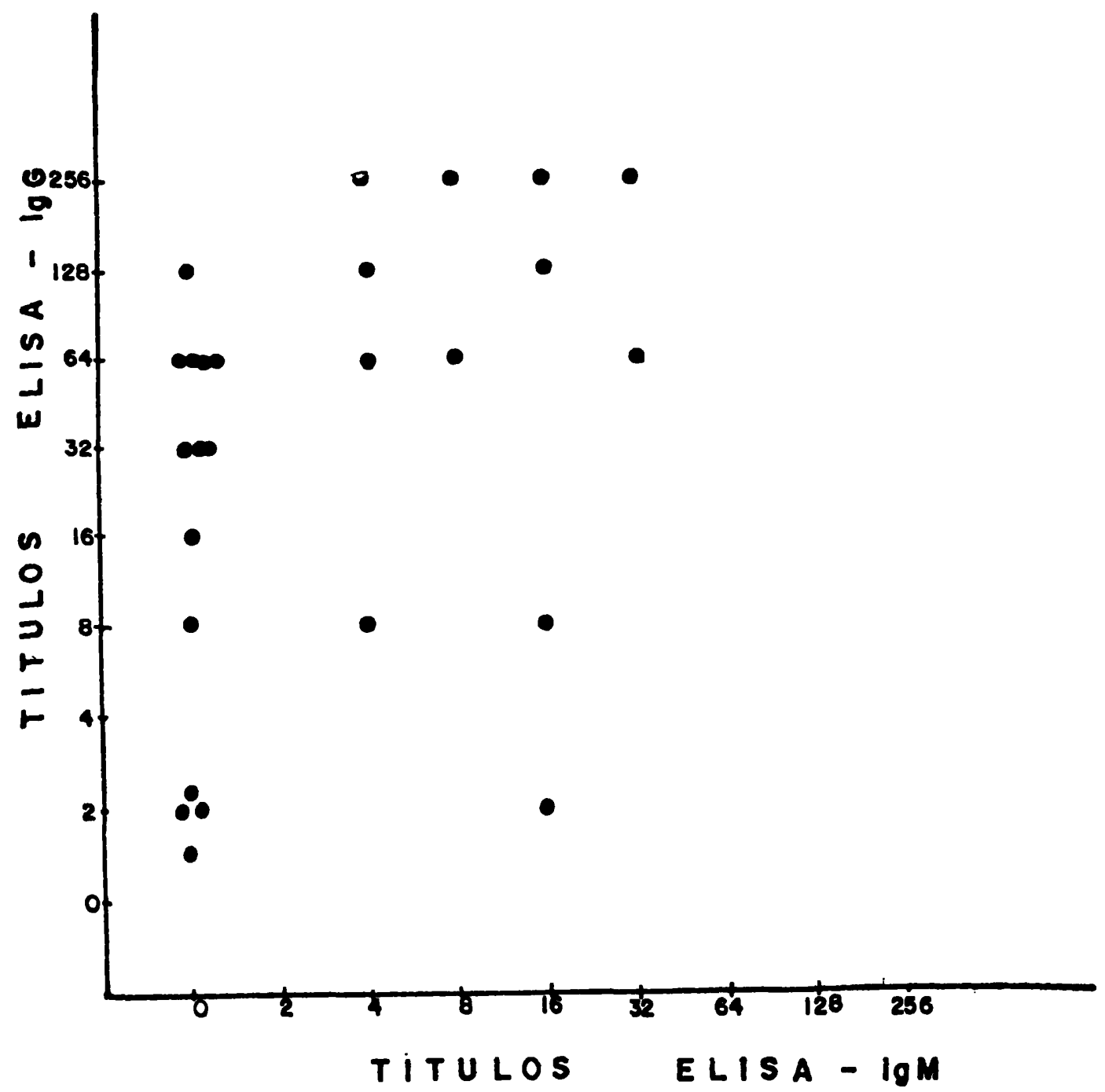

Fig. 1 - Resultados comparativos do teste ELISA-IgM e ELISA-IgG em 26 amostras de liquido cefalornaqueano de pacientes com neurocisticercose. 


\section{RESULTADOS}

Determinação da concentracão de polissacárides e proteinas do extrato antigenico - O extrato glicoproteico de $C$. cellulosae apresentou $640 \mu \mathrm{g} / \mathrm{ml}$ de polissacárides e 216 $\mu \mathrm{g} / \mathrm{ml}$ de proteínas. Testes imunoenzimaticos ELISA - Na tabela 1 são apresentados os resultados obtidos nos testes ELISA-IgM e ELISA-IgG para todas as amostras estur

\begin{tabular}{|c|c|c|c|c|c|c|}
\hline \multirow{3}{*}{ Teste } & \multicolumn{6}{|c|}{ Diagnóstico } \\
\hline & \multicolumn{2}{|c|}{ Neurocisticercose } & \multicolumn{2}{|c|}{ Neurossifilis } & \multicolumn{2}{|c|}{ Normais } \\
\hline & Reag. & Não-Reag. & Reag. & Não-Reag. & Reag. & Não-Reag. \\
\hline FLISA-IgM & 12 & 14 & 0 & 5 & 0 & 10 \\
\hline ELISA-IgG & 26 & 0 & 0 & 5 & 0 & 10 \\
\hline
\end{tabular}

\begin{tabular}{|c|c|c|c|c|c|}
\hline $\begin{array}{c}\text { Casos } \\
\text { No }\end{array}$ & ELISA-IgM & ELISA-IgG & RHA & RIF & RFC \\
\hline 1 & 0 & 64 & 16 & 8 & 2 \\
\hline 2 & 16 & 256 & 64 & 32 & 64 \\
\hline 3 & 0 & 32 & 128 & 16 & 8 \\
\hline 4 & 0 & 64 & 128 & 8 & 2 \\
\hline 5 & 32 & 256 & 128 & 22 & 8 \\
\hline 6 & 4 & 256 & 128 & 32 & 4 \\
\hline 7 & 8 & 64 & 64 & 4 & 8 \\
\hline 8 & 0 & 8 & 2 & 0 & 2 \\
\hline 9 & 0 & 64 & 16 & 8 & 16 \\
\hline 10 & 0 & 32 & 16 & 2 & 2 \\
\hline 11 & 4 & 8 & 4 & 4 & 4 \\
\hline 12 & 4 & 128 & 512 & 16 & 32 \\
\hline 13 & 0 & 1 & 1 & 0 & 2 \\
\hline 14 & 0 & 16 & 4 & 2 & 1 \\
\hline 15 & 32 & 64 & 16 & 8 & 16 \\
\hline 16 & 0 & 32 & 32 & 4 & 4 \\
\hline 17 & 16 & 2 & 1 & 0 & 0 \\
\hline 18 & 4 & 64 & 32 & 8 & 16 \\
\hline 19 & 8 & 256 & 256 & 8 & 32 \\
\hline 20 & 16 & 128 & 16 & 8 & 8 \\
\hline 21 & 0 & 2 & 8 & 4 & 2 \\
\hline 22 & 16 & 8 & 4 & 4 & 4 \\
\hline 23 & 0 & 64 & 64 & 16 & 4 \\
\hline 24 & 0 & 128 & 128 & 16 & 8 \\
\hline 25 & 0 & 2 & 2 & 0 & 0 \\
\hline 26 & 0 & 2 & 1 & 0 & 0 \\
\hline
\end{tabular}

Tabela 2 - Titulos em 26 amostras de LCR de casos de neurocisticercose, nos testes ELISA-IgM, ELISA-IgG, hemaglutinasão (RHA), imunofluorescência (RIF) e fixasão do complemento (RFC). 
dadas. Os níveis de anticorpos IgM e IgG anti-C. cellulosae nas 26 amostras de LCR com neurocisticercose estão expressas na figura 1. Tratamento dos LCR com 2-mercaptoetanol - Realizou-se em paralelo o teste ELISA-IgM com as amostras de LCR positivas tratadas e não tratadas, pelo 2ME, observando-se regativaçû́ das reacões para todos os LCR tratados. Comparação dos testes imunoenzimáticos com outros testes - Os LCR foram submetidos simultaneamente a reação de hemaglutinação, imunofluorescência e fixação do complemento para neurociscicercose. $\mathrm{N} 3$ tabela 2 são indicados os resultados nas 26 amostras de LCR com neurocisticercose distribuídas segundo títulos nos respectivos testes. Os 5 LCR de pacientes com neurossifilis e os 10 de pessoas aparentemente normais foram negativos para todos os restes imunológicos.

\section{COMENTARIOS}

A elevada freqüência de positividade que observamos para o teste ELISA-IgM na neurocisticercose (46\% de 26 casos) acentua a importância do estudo dos anticorpos IgM anti-cisticercos quanto ao seu significado para diagnóstico e acompanhamento terapêutico dessa parasitose. A alta sensibilidade do teste ELISA capaz de detectar baixos niveis de anticorpos circulantes permite a utilização de LCR sem concentrá-lo. A especificidade do teste foi comprovada pelas 12 amostras de LCR positivas que após tratamento com $2 \mathrm{ME}$ não mais reagiram no teste ELISA-IgM.

Os títulos dos LCR analisados pelo teste ELISA-IgM variaram de 4 a 32 e para o teste ELISA-IgG variaram de 1 a 256. Das 12 amostras de LCR que foram reagentes para os dois testes, duas apresentaram niveis de anticorpos IggM maiores que IgG. Observamos que no caso 17 pela reação de fixação do complemento $\mathrm{e}$ imunofluorescência as amostras eram negativas e com baixo título para hemaglutinação e ELISA-IgG. O caso 22 apresentcu todas as reações positivas, mas os niveis de IgM eram maiores que os de IgG. A tabela 2 permite observar que nem sempre os testes de fixação do complemento e imunofluorescência, que são clássicos para diagnóstico pelo LCR da neurocisticercose, apresentaram-se positivos salientando-se a importância de técnicas mais sensíveis e práticas como os testes imunoenzimáticos para a determinação dos níveis de anticorpos circulantes no LCR, como referido por Costa e col. ${ }^{9}$.

\section{RESUMO}

Demonstrou-se a presença de anticorpos da classe $\operatorname{IgM}$ anti-C. cellulosae em amostras de LCR de pacientes com neurocisticercose, pelo teste imunoenzimático ELISA. Este foi realizado em placas plásticas sensibilizadas com uma fração glicoproteica de cisticercos. Das 41 amostras de LCR estudadas, 26 pertenciam a pacientes com neurocisticercose, 5 a pacientes com neurossífilis e 10 a pessoas aparentemente normais. Nas 5 amostras de LCR de pacientes com neurossifilis e nas 10 de pessoas aparentemente normais foi negativo o teste ELISA-IgM. Dos 26 LCR de pacientes com neurocisticercose 12 (46,2\%) apresentaram anticorpos IgM anti-C. cellulosae com títulos que variaram de 4 
a 32. Essas 12 amostras de LCR quando submetidas ao tratamento com 2-mercaptoetanol tornaram-se negativas no teste ELISA-IgM. Compararam-se os niveis de anticorpos IgM e IgG anti-C. cellulosae detectados pelos respectivos testes imunoenzimáticos para todas as amostras estudadas e observou-se que, dos 12 LCR de pacientes com neurocisticercose reagentes pelos dois testes, dois apresentaram níveis de IgM mais elevados que de IgG. Paralelamente compararam-se os resultados dos testes ELISA com as reações de fixação do complemento, imunofluorescência e hemaglutinação para neurccisticercose.

\section{SUMMARY}

Cerebrospinal fluid IgM antibodies against Cysticercus cellulosae detection in neurocysticercosis through ELISA immunoenzymatic assay.

IgM antibodies against Cysticercus cellulosae in the cerebrospinal fluid (CSF) was demonstrated by ELISA immunoenzymatic assay in neurocysticercosis. CSF samples of 41 patients were analyzed for this purpose. Diagnosis was neurocysticercosis in 26 and neurosyphilis in 5; abnormalities were not registered in the other 10 cases. Neurosyphilis samples and no-abnormalities samples were considered as control groups. ELISA IgM assay for cysticercosis was negative in all CSF samples of control groups and it was positive in 12 of the $26 \mathrm{CSF}$ samples of the neurocysticercosis group (46.2\%) Titers ranged from 4 till 32. Positive results were no more obtained after previous treatment of CSF samples by 2-mercaptoetanol. ELISA IgM and IgG titers were compared. IgM titers were higher than IgG titers in two cases. Results obtained werc compared to those found through complement fixation, immunofluorescence and hemagglutination tests for the diagnosis of neurocysticercosis.

\section{REFERENCIAS}

1. ARAMBULO III, P.V.; WALES, K.W.; BULLOCK, S. \& KAGAN, I.G. -Serodiagnosis of human cysticercosis by microplate enzyme-linked immuno specific assay (ELISA). Acta tropica 35:63, 1978.

2. AVRAMEAS, S. \& TERNYNCK, T. - The cross linked of proteins with glutaraldehyde and its use for the preparation of immunoadsorbents. Inımunochemistry 6:53, 1969.

3. BASSI, G.E.; CAMARGO, M.E.; BITTENCOURT, J.M.T. \& GUARNIERE, D.B. Rcação de imunofluorescência com antígenos de Cysticencus cellulosae no líquido cefalorraqueano. Neurobiologia 42:165, 1979.

4. BIAGI, F.F.; NAVARReTe, F.; PINA, A.; SANTIAGO, A.M. \& TAPIAL, L. Estudio de tres reacciones serológicas en el diagnóstico de la cisticercosis. Rev. med. Hosp. General (México) 11-12:501, 1961.

5. BIAGI, F.F. \& TAY, J.A. - A precipitation reaction for the diagnostic of cysticercosis. Amer. J. trop. Med. Hyg. 7:63, 1958.

6. CAMARGO, M.E.; HOSHINO-SHIMIZU, S. \& SIQUEIRA, G.R U. - Hemagglutination with preserved, sensitized cells, a practical test for routine serologic diagnosis of American trypanosomiasis. Rev. Inst. Med. trop. São Paulo 15:81, 1973.

7. CLARK, H.F. \& SHEPARD, C.C. - A dialysis technique for preparing fluorescent antibody. Virology 20:642, 1963.

8. COSTA, J.M. - Teste imunoenzimático (ELISA) no diagnóstico dá neurocisticercose. Tese. Universidade de São Paulo, São Paulo, 1983. 
9. COSTA, J.M.; FgrRgIRA, A.W.; MAKINO, M.M. \& CAMARGO, M.E. - Spinal fluid immunoenzymatic assay (ELISA) for neurocisticercosis. Rev. Inst. Med. trop. São Paulo, 24 :337, 1982.

10. DIWAN, A.R.; COKER-VANN, M.; BROWN, P.; SUBIANTO, D.B.; YOLKEN, R.; DESOWITZ, R.; FSCOBAR, A.; GIBBS Jr.; C.J. \& GAJDUSEK, D.C. - Enzyme-linked immunosorbent assay (ELISA) for the detection of antibody to cysticerci of Taenia solium. Amer. J. trop. Med. Hyg. 31:364, 1982.

11. GRISOLIA, J.S. \& WIEDERHOLT, W.C. - CNS cysticercosis. Arch. Neurol. $39: 540,1982$.

12. KOLMFR, J.A.; SPAULDING, E.M. \& ROBINSON, H.W. - Approved Laboratory Technic. Ed.5. Appleton Century Crofts, New York, 1951, pg. 797.

13. LANGE, O. - Síndrome liquórica da cisticercose encefalomeníngea. Rev. Neurol. Psiquiat. São Paulo 6:35, 1940.

14. LIVRAMENTO, J.A. - Contribuição de reações de imunofluorescência no liquido cefalorraqueano ao estudo da neurocisticercose. Arq. Neuro-Psiciuiat. (São Paulo) $39: 261,1981$.

15. LOWRY, V.H.; ROSEMBROUCH, N.J.; FARR, A.L. \& RANDAL, R.J. - Protein measurement with the Folin phenol reagent. J. biol. Chem. 193:265, 1956.

16. MACHADO, A.J.; CAMARGO, M.E. \& HOSHINO, S. - Reação de imunofluorescência para cisticercose com partículas de Cysticercus cellulosae fixadas a laminas de microscopia. Rev. Soc. bras. Med. trop. 7:181, 1973.

17. Martfinez, B. - Diagnóstico serológico de la cisticercosis. Prensa med. mex. 28:26, 1963.

18. MARTINEZ-CAIRO, S.; RUIZ-MACIAS, C.; LOPES-ROMAN, M. \& MATFOS-GOMEZ, H. - Usefulness of concentrated CSF hemagglutination technique for the diagnosis of cerebral cysticercosis. Arch. invest. médica (Mexico) 11:347, 1980.

19. MARTIRANI, I.; HOXTER, G.; WAJCHFNBERG, B.L.; MARIANI, I. \& CINTRA, A.R.U. - Determination of polissacharide hexoses and hexosamines in normal human sera. J. Lab. clin. Med. 54:773, 1959.

20. MCCORMICK, G.F.; ZEE, C.S. \& HEIDEN, J. - Cysticercosis cerebri: rewlew of 127 cases. Arch. Neurol. 39:534, 1982.

21. MICHELI, A. \& ISLIKER, H. - Cleavage of gamma-M-glcbulin by means of reducing enzyme systems. Immunochemistry $3: 385,1966$.

22. NASH, T.E.; PRESCOTT, B. \& NEVA, F.A. - The characteristics of a circulating antigen in schistosomiasis. J. Immunol. 112:1500, 1974.

23. REIS, J.B.; BEI, A. \& REIS FILHO, J.B. - Nossa experiência com a reação de fixaçăo de complemento pela técnica de Wadsworth, Maltaner e Maltaner adaptada ao líquido cefalorraqueano para o diagnóstico da siftlis e da cisticercose. Rev. paul. Med. 62:118, 1963.

24. SPINA-FRANCA, A. \& KLEINE, T.O. - Clinical validity if IgG, IgM;, IgA and agarose gel electrophoresis of protcins in CSF in diagnosing neurocysticercosis. In: E. Levy (ed.): Advances in Pathology. Pergamon Press, Oxford, 1982, pg. 519.

25. WILSON, M.B.; NAKANE, P.K. - Recent developments in the periodate method of conjugating horseradish peroxidase (HRPO) to antibodies. In W. Knapp, $K$. Holubar \& G. Wick (eds.): Imunofluorescence and Related Techniques. North-Holland Biomedical, Amsterdam, 1978, pg. 215.

Centro de Ciencias Biomédiaas - Campus Umuarama, Universidade Irederal de Uberlandia - 38400, Uberlandia, MG - Brasil. 